\title{
NEUROPATHIC PAIN AMONG PATIENTS WITH SICKLE CELL DISEASE
}

\author{
Jordana Alícia Silveira Lopes ${ }^{1, \star}$, Daniela de Oliveira Werneck Rodrigues², Amanda do Carmo Gusmão ${ }^{3}$, Augusto Cézar Apolinário \\ dos Santos ${ }^{4}$, Nathalia Noyma Sampaio Magalhães ${ }^{3}$, Olivia Franco dos Santos ${ }^{1}$, Renato Lourenço de Medeiros ${ }^{3}$, Rodrigo de \\ Martin Almeida², Tássia Mariana Moreira da Paz ${ }^{4}$, Thaís Sette Espósito ${ }^{4}$
}

1.Universidade Federal de Juiz de Fora, Juiz de Fora (MG), Brazil. 2.Fundação Hemominas, Juiz de Fora (MG), Brazil. 3.Faculdade de Ciências Médicas e da Saúde de Juiz de Fora, Juiz de Fora (MG), Brazil. 4.Centro Universitário Presidente Antônio Carlos, Juiz de Fora (MG), Brazil.

*Corresponding author: jordanalopes6@gmail.com

\section{BACKGROUND}

Vaso-occlusive crisis (VOC), the most prevalent clinical manifestation of sickle cell disease (SCD), is traditionally characterized as nociceptive; however, several patients reported symptoms of neuropathic pain, often between 25 and $40 \%$ in adolescents and adults with SCD. Age, female gender and use of hydroxyurea have been reported to be positively associated with neuropathic pain in SCD. The literature suggests that neuropathic pain is underdiagnosed and that specific drugs for this type of suffering are extremely underused.

\section{MATERIALS AND METHODS}

Longitudinal study that evaluated 275 patients with SCD at Hemominas Juiz de Fora. The variables analyzed were: age, gender, color, genotype, absenteeism, smoking, drug use, presence of VOC and neuropathic pain. The information was extracted from the database of the REDS III study. A descriptive analysis was carried out from November/2013 to March/2015. The research was approved by the Research Ethics Committee No. 419,415/2013.

\section{RESULTS}

Of the 275 patients analyzed, 151 (54.9\%) were children and 124 (45.1\%) adults with a slight predominance of females (54.2\%). Most patients declared themselves to be brown (53.3\%) and 26.6\%, black. As for the genotype, $68.4 \%$ wereSS/SBO thalassemia, 28\% SC and $3.6 \%$ $\mathrm{SB}+$ thalassemia. Regarding absenteeism, children missed 151 school days and adults missed 124 days of work due to pain. Among adults, $26.5 \%$ of women used tobacco and in the male group $35.4 \%$ were smokers. Regarding alcoholism, $51.6 \%$ of patients consumed alcoholic beverages and $6.5 \%$ used marijuana and $1.6 \%$ reported using crack. There was no report of injecting drug use. Regarding pain, $84.8 \%$ of children and $96 \%$ of adults were diagnosed with VOC, with an average of hospital admissions of $3.1 \%$ in children and $4.9 \%$ in adults. Avascular necrosis had a prevalence of $4 \%$ under the age of 18 and $22.6 \%$ in adults, the average age for this diagnosis was 26.3 years. In the 151 children evaluated, neuropathic pain was not identified, while 5 of 124 adults (4\%) had this diagnosis. The analysis of medication use showed that $11.8 \%$ of patients needed analgesics for more than 30 days and the treatment for neuropathic pain with antidepressants was observed in $1 \%$.

\section{CONCLUSION}

Chronic pain conditions, such as neuropathic pain, can be underestimated in SCD. Systematic assessment of the patient with a multidisciplinary team is necessary to intervene in the causes that generate painful stimuli triggered by chronic inflammation and hemolysis, enabling improvement in quality of life and reduction of suffering in SCD.

\section{REFERENCES}

1. Sharma D, Brandow AM. Neuropathic pain in individuals with sickle cell disease. Neurosci lett. 2020;714:134445. https://doi.org/10.1016/j. neulet.2019.134445

2. Asnani MR, Francis DK, Brandow AM, Gabbadon CEH, Ali Al. Interventions for treating neuropathic pain in people with sickle cell disease. Cochrane Database of Syst Rev. 2019;7(7): CD012943. https://doi.org/10.1002/14651858.cd012943.pub2

3. Antunes FD, Propheta VGS, Vasconcelos HA, Cipolotti R. Neuropathic pain in patients with sickle cell disease: a cross-sectional study assessing teens and Young adults. Ann Hematol. 2017;96(7):1121-5. https://doi.org/10.1007/s00277-017-2984-z

4. Ballas SK, Darbari DS. Review/overview of pain in sickle cell disease. Complement Ther Med. 2020;49:102327. https://doi.org/10.1016/j. ctim.2020.102327 